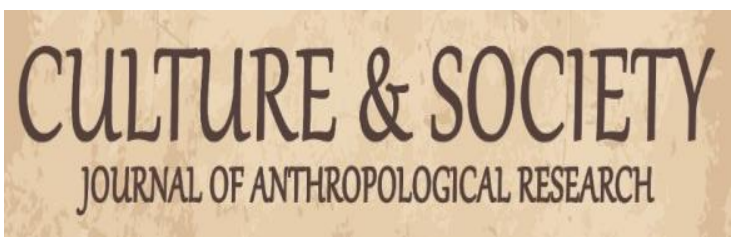

Culture \& Society: Journal of Anthropological Research

VOL. 2 NO. 1 SEPTEMBER 2020

http://culture.ppj.unp.ac.id

Email: culture@ppj.unp.ac.id

ISSN: 2686-343X (E-ISSN) 2686-3421 (P-ISSN)

DOI: https://doi.org/10.24036/csjar.v2i1.49

\title{
Dampak Boyband EXO Style Bagi komunitas EXO-L Sumbar
}

\author{
Elwa Moneta ${ }^{1}$, Erda Fitriani ${ }^{2}$ \\ ${ }_{1,2}^{1}$ Universitas Negeri Padang \\ Email: elwamoneta02@gmail.com, fitriani_cim@fis.unp.ac.id
}

\begin{abstract}
Abstrak
Penelitian ini bertujuan untuk menjelaskan dampak Boyband EXO Style bagi komunitas EXO-L Sumbar di Kota Padang. Temuan penelitian dianalisis dengan menggunakan teori Imitasi yang dikembangkan oleh Gabriel Tarde. Penelitian ini menggunakan pendekatan kualitatif dengan tipe penelitian studi kasus. Hasil penelitian ini mengungkapkan bahwa dampak Boyband EXO style bagi Komunitas EXO-L Sumbar diantaranya (1) anggota komunitas mengikuti style Idol K pop, mulai dari cara berpakaian hingga make-up (2) berbahasa (Korea, Jepang, China dan Inggris) menjadi lancar karena anggota Komunitas EXO-L Sumbar menyukai lagu-lagu Boyband EXO (3) mengembangkan Hobi bernyanyi dan dance dengan musik-musik Boyband EXO (4) perilaku Konsumtif, membeli barang-barang yang berkaitan dengan Boyband EXO, (5) anggota meniru cara hormat orang korea serta rasa sensitif terhadap berita Boyband EXO. (6) kurang disiplin, lupa dengan waktu dan lupa untuk melakukan yang harus dilakukan karena menaruh perhatian lebih kepada Boyband EXO.
\end{abstract}

Kata kunci: EXO, EXO-L, budaya korea, dampak dan lifestyle

\section{Abstract}

This study aims to explain the impact of Boyband EXO Style for community members EXO-L Sumbar in the city of Padang. The researchers' findings were analyzed using the Imitation theory developed by Gabriel Tarde. This study uses a qualitative approach with a case study type research. The results of this study reveal that the impact of the EXO Boyband style for the West Sumatra EXO-L Community includes (1) community members following the K pop Idol style, from how to dress to make-up (2) the language (Korean, Japanese, Chinese and English) becomes fluent. because members of the West Sumatra EXO-L Community like the songs of the EXO Boyband (3) developing a hobby of singing and dancing with EXO Boyband music (4) Consumptive behavior, buying items related to EXO Boyband, (5) members imitating respectful ways Korean people and a sense of sensitivity to the news of the EXO Boyband. (6) lack of discipline, forgetting about time and forgetting to do what to do because they pay more attention to boyband EXO

Keywords: EXO, EXO-L, impact, korean culture and lifestyle

\begin{tabular}{|l|l|l} 
Received: July 30, 2020 & Revised: August 13, 2020 & Published: August 14, 2020
\end{tabular}

Culture \& Society: Journal of Anthropological Research Vol. 2, No. 1, Th. 2020 


\section{Pendahuluan}

Boyband dan Girlband Korea memiliki daya tarik yang kuat terhadap orang-orang sehingga mereka banyak disukai, mulai dari wajah yang tampan dan cantik, cara berpakaian atau style dari mereka yang sangat menarik sehingga gaya mereka diikuti oleh penggemar mereka. EXO adalah salah satu Boyband dari Korea Selatan, EXO merupakan salah satu produk K-Pop yang didebutkan oleh SM Entertainment pada tahun 2012 (Rahmawati, 2017). EXO memiliki nama penggemar yaitu dengan sebutan EXO-L. Kota Padang salah satu Kota di Indonesia yang juga merasakan perkembangan K-pop tersebut, bahkan sudah mengikuti gaya modern Korea Selatan. Masyarakat juga tidak sedikit menyukai EXO, karena cukup banyak jumlah penggemar EXO di Padang maka mereka berinisiatif membuat komunitas dengan nama EXO-L Sumatera Barat atau disingkat EXO-LSumbar, yang dibentuk pada tahun 2015. Jumlah anggota komunitas ini hingga Januari 2020 berjumlah 63 orang, mereka menggunakan media seperti WhatsApp dan Instagram, mereka memiliki akun grup chat di media sosial WhatsApp dan Instagram.

Berdasarkan penjelasan di atas terdapat beberapa masalah yang ditimbulkan dari perkembangan K-pop Sama halnya dengan bukan budaya asing yang menyesuaikan diri, namun kebudayaan yang dimasuki yang mengalami perubahan (Febrianto \& Fitriani, 2012). Salah satunya munculnya Boyband EXO sehingga terdapat Komunitas EXO-L di Kota Padang, diantaranya masyarakat yang menggemari Boyband EXO ataupun Boyband dan Girband dari Korea Selatan yang mengikuti gaya kehidupan dari idolanya sehingga tidak jarang gaya tersebut ditiru karena bagi mereka yang ada pada diri dan kehidupan idolanya, menarik perhatian mereka mulai dari pakaian hingga aktivitas serta perilaku dari idola Korean Selatan. Di sisi lain anggota komunitas EXO yang bertemu satu sama lain juga tidak jarang menghasilkan sebuah informasi yang diinginkan atau dibutuhkan baik informasi Boyband EXO atau seputar tentang Korea.

Menurut Koentjaraningrat, komunitas adalah suatu kesatuan hidup manusia yang menempati suatu wilayah nyata dan berinteraksi menurut sistem adat-istiadat, dan terikat oleh identitas komunitas (Koentjaraningrat, 2013), Komunitas dalam tulisan ini merujuk pada kelompok sosial yang terbentuk di wilayah yang sama dan saling berinteraksi tentang hal yang sama sesama mereka sebagai bentuk mereka dalam komunitas yang sama, individu-individu yang memiliki kesamaan dalam hal yang disukai. Dalam hal ini komunitas adalah istilah yang secara konseptual merupakan kelompok sosial. Menurut Cristo dalam Hariyati (2015) dampak adalah suatu yang diakibatkan oleh sesuatu yang dilakukan, bisa positif atau negatif atau pengaruh kuat yang mendatangkan akibat baik negatif maupun positif (Hariyati, 2015). Menurut Robert Y. Kwick dalam Misbach (2017) perilaku diartikan sebagai suatu aksi dan reaksi organisme terhadap lingkungannya, hal ini berarti bahwa perilaku baru akan terwujud bila ada sesuatu yang diperlukan untuk menimbulkan tanggapan yang disebut rangsangan, dengan demikian maka suatu rangsangan tertentu akan menghasilkan perilaku tertentu pula (Misbach, 2017).

Peneliti melakukan penelusuran terhadap penelitian-penelitian terdahulu. Penelitian tentang perkembangan budaya K-pop dan Boyband Korea Selatan yang sudah dikemukakan oleh penelitian sebelumnya. Berikut beberapa penelitian relevan : Penelitian yang berjudul "Komunitas EXO-L Yogyakarta (Studi Kasus Dinamika Penggemar K-pop di Yogyakarta) pada tahun 2012 oleh Novriasonnya Paramita Wijaya (Wijaya, 2017). Penelitian selanjutnya yaitu berjudul “ Analisis Gaya Hidup dalam Mengimitasi Budaya Pop Korea Melalui Televisi (Studi Pada Siswa SMA Negeri 9 Manado) Oleh Olivia M. Kaparang pada tahun 2013 (Kaparang, 2013).

Penelitian tentang Dampak Boyband EXO style bagi komunitas EXO-L Sumbar dikaji dengan teori imitasi dari Gabriel Tarde. Menurut Gabriel Tarde semua saling hubungan sosial itu berkisar pada proses imitasi; bahkan semua pergaulan antar manusia hanyalah berdasarkan proses imitasi (Gerungan, 2010). Masyarakat itu tidak lain dari pengelompokkan manusia di mana individu-individu yang satu mengimitasi yang lain dan sebaliknya. Gabriel Tarde juga berpendapat perilaku imitasi terjadi karena ada tokoh idola yang dijadikan sebagai model untuk ditiru (Sella, 2013). 


\section{Metode Penelitian}

Penelitian ini dilakukan di Kota Padang yaitu tempat Komunitas EXO-L Sumbar, Komunitas EXO-L sumbar tidak memiliki tempat yang tetap, namun mereka akan memilih lokasi jika mereka akan melakukan suatu perkumpulan, mereka akan mencari tempat yang strategis dan bisa menampung jumlah anggota mereka yang tidak sedikit, seperti cafe atau pusat perbelanjaan di daerah Kota Padang, jumlah informan pada penelitian ini sebanyak 10 informan, dengan kriteria informan anggota EXO-L yang berada dalam komunitas EXO-L yang mengikuti dan meniru style Boyband $\mathrm{EXO}$ dan informan bersedia diwawancarai dan memberikan informasi yang peneliti butuhkan. Penelitian dilakukan dari 12 Januari sampai 8 Maret 2020.

Pendekatan yang dilakukan dengan pendekatan penelitian kualitatif dengan tipe studi kasus. Perolehan data didapatkan dengan melalui observasi, wawancara mendalam dan studi dokumentasi (Sugiyono, 2008). Observasi pada penelitian ini menggunakan observasi partisipatif yaitu peneliti terlibat dengan kegiatan sehari-hari orang yang sedang diamati atau yang digunakan sebagai sumber penelitian (Sugiyono, 2017). Teknik pemeriksaan keabsahan data dalam penelitian ini menggunakan trianggulasi sumber (Bungin, 2012). Agar data yang diperoleh dilapangan valid maka peneliti melakukan triangulasi sumber berupa pertanyaan kepada anggota Komunitas EXOL yang ikut serta dalam acar komunitas tersebut. Dalam penelitian ini, penulis melakukan wawancara yang didukung dengan kegiatan observasi pada saat wawancara dilakukan. Wawancara yang dilakukan yaitu mengajukan pertanyaan yang relatif sama kepada informan yang berbeda. Kemudian setelah data yang diperoleh dianalisis dengan menggunakan analisis interaktif oleh Milles dan Huberman dengani langkah mengumpulkan data, reduksi data, displaym data, dan menarik kesimpulan/verifikasi. Menurut Wende et al. (2018) proses aktivitas dalam analisis data ini, dilakukan secara terus menerus pada setiap tahap penelitian sampai penelitian ini selesai.

\section{Hasil dan Pembahasan}

\section{Dampak Boyband EXO Style Bagi Komunitas EXO L Sumbar}

EXO-L adalah Sebutan untuk nama fandom atau penggemar yang mengidolakan Boyband EXO. Boyband EXO adalah salah satu boyband Korea Selatan yang dibentuk pada tahun 2011 dan debut pada tahun 2012. Bagi pengemar Boyband EXO membuat komunitas atau kelompokkelompok berdasarkan kawasan. Untuk wilayah Sumatara Barat terdapat komunitas EXO-L Sumbar yang merupakan orang-orang yang memiliki kecintaan terhadap grup Boyband EXO. Anggota EXO-L yang berada di Kota Padang tergabung dalam grup EXO-L Sumbar, yang biasanya mereka terhubung dengan adanya media sosial seperti facebook, Intagram, whatsApps. Anggota komunitas ini juga melakukan pertemuan di cafe-cafe di Kota Padang dan melakukan berbagai evebt atau pun sekedar bertemu kangen dengan sesama pengemar Boyband EXO. Kecintaan pengemar terhadap Boyband EXO menambah kecintaan mereka terhadap budaya Korea, sehingga memberikan dampak terhadap anggota komunitas, yang dalam hal ini difokuskan kepada komunis EXO-L Sumbar di Kota Padang. Di bawah ini dibahas tentang dampak Boyband EXO Style bagi Komunitas EXO-L Sumbar.

\section{Mengikuti style idol K Pop}

Perkembangan bentuk style dari beberapa negara makin mudah dilihat dan diakses, salah satunya Korea Selatan, tidak sedikit orang-orang mengikuti style. Bagi anggota Komunitas EXOL Sumatera Barat pun juga mengikuti gaya dari Boyband EXO dan gaya anak muda Korea Selatan, mereka mengakui bahwa tertarik dengan tampilan dan gaya anak-anak muda Korea Selatan yang menurut mereka yang modis dan natural dari pakaian, aksesorise bahkan hingga make-up. 


\section{Make-Up}

Make-up banyak digandrungi oleh anak-anak muda terutama perempuan karena bisa menunjang penampilan wajah mereka yang akan terlihat cerah dan mereka merasa make-up Korea atau make-up yang seperti idolanya cocok untuk mereka walaupun mereka masih duduk dibangku sekolah. Dari pernyataan EM, NI dan NZ mereka menyukai makeup dari Korea Selatan karena terlihat natural untuk mereka walaupun masih berstatus pelajar serta cara bermake-up tersebut bisa mereka gunakan juga untuk sekedar pergi untuk jalan-jalan atau untuk pergi bermain bersama teman. Selain make-up, perawatan kulit dan wajah juga mereka lakukan seperti masyarakat Korea Selatan karena kulit meenjadi sehat.

\section{Pakaian}

Mereka mengetahui berbagai Style Korea dari idola mereka, ada diantara mereka yang ingin mengikuti dan ada yang hanya sebagian kecil saja yang diikuti seperti berpakaian lebih rapi saja. Mereka juga memakai jenis-jenis produk kecantikan dari Korea, selain tentang kecantikan, berbusana mereka juga melakukan, yang menurut mereka cocok dengan pribadi mereka dan menyesuaikan dengan kondisi mereka seperti yang memakai jilbab.

Cara mereka mengimitasi yaitu setelah mengenal Boyband EXO mereka menjadi mengikuti Style orang Korea selatan. Dari pernyataan informan bisa dikaji dengan teori Imitasi Gabriel Tarde, yaitu seseorang memiliki perasaan yang kuat untuk menandingi (menyamai atau bahkan melebihi) tindakan orang disekitarnya, Gabriel tarde juga berpendapat perilaku imitasi terjadi karena ada tokoh idola yang dijadikan sebagai model untuk ditiru (Sella, 2013). mereka mengetahui berbagai Style Korea dari idola mereka, ada diantara mereka yang ingin mengikuti dan ada yang hanya sebagian kecil saja yang diikuti seperti berpakaian lebih rapi saja. Mereka juga memakai jenis-jenis produk kecantikan dari Korea, selain tentang kecantikan, berbusana mereka juga melakukan, yang menurut mereka cocok dengan pribadi mereka dan menyesuaikan dengan kondisi mereka seperti yang memakai jilbab.

\section{Berbahasa (Korea, Jepang, China dan Inggris) Menjadi Lancar}

Berbagai jenis musik mudah didengarkan pada saat ini, mendengarkan lagu membuat seseorang nyaman sesuai dengan genre yang disukai, dengan lirik yang lebih menginspirasi dan memotivasi, seseorang yang menyukai musik diyakini mengenal beberapa jenis musik dan bahkan bisa bernyanyi walaupun dengan bahasa yang berbeda membuat seseorang ingin belajarar beberapa bahasa agar pesan lagu tersebut bisa diketahui. pernyataan informan NI, RA dan AY yang ingin mempelajari bahasa Korea, Jepang, China dan Inggris agar bisa mengerti setiap lagulagu EXO dan acara atau video-video tentang EXO

Dari pernyataan informan bisa dikaji dengan teori Imitasi Gabriel Tarde, yaitu seseorang memiliki perasaan yang kuat untuk menandingi (menyamai atau bahkan melebihi) tindakan orang disekitarnya, Gabriel tarde juga berpendapat perilaku imitasi terjadi karena ada tokoh idola yang dijadikan sebagai model untuk ditiru (Sella, 2013). Di sini anggota Komunitas EXO-L ingin mempelajari bahasa yang sama digunakan oleh Boyband EXO, karena lagu-lagu EXO juga menggunakan beberapa bahasa yaitu Bahasa Korea, Jepang, China dan Inggris, mereka meniru Boyband EXO untuk menggunakan beberapa bahasa tersebut karena termotivasi dari lagu-lagu atau beberapa acara dari Boyband EXO yang susah dimengerti jika tidak memakai terjemahannya.

\section{Mengembangkan Hobi}

Hobi yang dimiliki oleh anggota Komunitas EXO rata-rata hampir sama yaitu dance dan bernyanyi, Berbagai jenis musik mudah didengarkan pada saat ini. Berbagai jenis musik dari berbagai negara yang masuk kenegara indonesia membuat industri musik menjadi semakin berkembang dan bervariasi (Izzati \& Armando, 2014), mereka yang sama-sama bertemu di Komunitas EXO, menjadi bisa berbagi hal yang mereka sukai, hingga mereka memiliki teman yang sehobby. Mereka berawal menyukai EXO dan lagu-lagunya membuat mereka ingin

Culture \& Society: Journal of Anthropological Research Vol. 2, No. 1, Th. 2020 
melakukan hal yang sama seperti kemampuan Boyband EXO spereti bernyayi dan dance, mereka sebelumnya tidak bisa bernyanyi atau dance menjadi bisa setelah menyukai EXO, begitupun yang sudah pandai menjadi lebih pandai dalam bernyanyi dan dance.

Seperti yang diungkapkan dalam teori Imitasi Gabriel Tarde, yaitu seseorang memiliki perasaan yang kuat untuk menandingi (menyamai atau bahkan melebihi) tindakan orang disekitarnya, Gabriel tarde juga berpendapat perilaku imitasi terjadi karena ada tokoh idola yang dijadikan sebagai model untuk ditiru (Sella, 2013). Mereka berawal menyukai EXO dan lagulagunya membuat mereka ingin melakukan hal yang sama seperti kemampuan Boyband EXO spereti bernyayi dan dance, mereka sebelumnya tidak bisa bernyanyi atau dance menjadi bisa setelah menyukai EXO, begitupun yang sudah pandai menjadi lebih pandai dalam bernyanyi dan dance.

\section{Perilaku Konsumtif}

Menurut anggota-anggota yang berada dalam Komunitas EXO-L Sumatera Barat menyukai Boyband EXO bisa membuat mereka mengumpulkan uang untuk membeli barang-barang yang diinginkan, seperti album EXO, lightstick EXO, merchendise EXO dan barang-barang yang berkaitan dengan Boyband EXO yang tentunya harganya tidaklah murah, mereka melakukan itu agar tidak meminta uang pada orang tua untuk membeli barang-barang yeng berhubungan dengan EXO. mereka membutuhkan materil dalam hal menyukai idola mereka menjadikan mereka memiliki sifat yang boros hingga tidak jarang dari mereka yang meminjam uang kepada teman dan mereka yang tidak memiliki uang lebih akan meminta kepada orang tua mereka, selain dalam bentuk barag mereka juga membutuhkan uang untuk kuota internet mereka, yang menurut mereka membutuhkan kuota lebih untuk mencari informasi idola mereka.

Teori Konsumtif dari Jean Paul Baudrillard yang mengatakan bahwa adanya nilai guna, nilai tanda, dan simulacra dalam setiap kegiatan konsumsi yang dilakukan, Baudrillard juga menjelaskan bahwa perilaku konsumsi saat ini tidak hanya dipengaruhi oleh faktor-faktor yang murni ekonomis dan berdasarkan pilihan rasional saja, akan tetapi terdapat sistem budaya dan sistem pemaknaan sosial yang mampi mengarahkan pilihan individu atas suatu komoditas. Berdasarkan teori bahwa anggota Komunitas EXO-L yang membeli barang-barang yang berkaitan dengan Boyband EXO karena mereka memberi makna berbeda terhadap Boyband EXO, mereka juga merasa bahwa untuk menjadi penggemar EXO maka mereka juga harus punya barang yang sama, mereka menandai diri mereka sebagai EXO-L dengan barang-barang yang berhubungan dengan Boyband EXO, selain itu mereka juga terobsesi dengan Boyband EXO. Mereka juga membeli karena melihat barang tersebut juga dibeli sesama penggemar EXO, atau karena mereka hanya sekedar suka, karena prilaku tersebut mereka menjadi banyak pengeluaran, jika tidak bisa mengkontrol pengeluaran, mereka akan meminta ke orang tua atau berhutang dengan temannya, namun ada juga yang iyuran degan teman-temannya untuk membeli barang-barang yang berkaitan dengan Boyband EXO.

\section{Meniru cara hormat orang Korea}

Perilaku seseorang bisa terbentuk karena lingkungan sekitar, beitupun dengan anggota Komunitas EXO-L Sumbar yang sadar akan perubahan sikap mereka setelah menjadi pengemar Boyband EXO, bahkan diantara mereka juga melakukan perilaku yang sama dengan Boyband EXO, atau karena mereka menyukai Boyband EXO mereka juga menyukai sikap/perilaku dari orang Korea Selatan. Dampak Boyband EXO Style pada anggota Komunitas EXO-L SUMBAR sebagai berikut:

Di Korea, rasa hormat dan sopan santun menjadi aspek penting dalam kehidupan (Seob, 2014). Rasa hormat dan sopan di Korea patut dicontoh oleh siapapun karena untuk menjalankan kehidupan yang baik, hingga terjalin rasa saling menghargai satu sama lain. Pada Komunitas EXO-L, para anggotanya mengaku sangat kagum dengan sikap orang-orang Korea, bahakan mereka belajar bersikap seperti orang Korea. Menurut VR menjadi penggemar K-pop bisa

Culture \& Society: Journal of Anthropological Research Vol. 2, No. 1, Th. 2020 
membedakan perbedaan pada manusia tidak memandang fisik atau ras, bisa bersatu untuk saling tolong menolong dan kerja sama dalam suatu kegiatan yang lebih positif. Mereka terinspirasi baik dari idola maupun sesama penggemar, bahkan bisa terinspirasi dari sikap, perilaku, kegiatan atau pengetahuan yang bisa dipelajari, serta menghilangakan perbedaan yang bersifat menyudutkan.

\section{Rasa sensitif terhadap berita boyband EXO}

Emosi adalah sebagai suatu keadaan yang terangsang dari organisme mencakup perubahanperubahan yang disadari (Manizar, 2016). Dapat disimpulkan bahwa emosi adalah keadaan yang ditimbulkan oleh seseorang atau situasi tertentu yang ditunjukkan melalui ekspresi kejasmanian (Fitri \& Adelya, 2017). Emosional seseorang bisa berubah dalam situasi tertentu dan berkaitan dengan hal tertentu pula, sama halnya dengan EXO-L yang mengakui semenjak menjadi menjadi K-popers menjadi lebih emosional, mudah senang, mudah sedih ataupun marah bahkan mereka bisa saja menghayalkan yang pastinya mereka akui hanya hayalan saja tidak jadi kenyataan.

Gabriel Tarde menyatakan bahwa seseorang memiliki perasaan yang kuat untuk menandingi (menyamai atau bahkan melebihi) tindakan orang disekitarnya, Gabriel tarde juga berpendapat perilaku imitasi terjadi karena ada tokoh idola yang dijadikan sebagai model untuk ditiru (Sella, 2013). Anggota EXO-L mereka merasa beruntung bisa mengenal Boyband EXO dan dijadikan panutan dari sisi perilaku, karena menurut mereka tidak hanya style saja yang bisa ditiru tapi perilaku mereka pun juga positif bahkan yang mereka tau kesopanan dan menghormati orang lain adalah perilaku yang penting di Korea Selatan. Perilaku idola mereka yang sopan, menghargai, menghormati, disiplin, kerja keras, cara berbicara yang sopan serta terus berusaha membuat mereka ingin menerapkannya ke kehidupan sehari-hari mereka dan menjadi pelajaran dalam berperilaku dan bersikap.

\section{Kurang Disiplin}

Menyukai sesuatu hal secara berlebihan bisa membuat seseorang lupa waktu bahkan tidak sadar telah membuang-buang waktu, rasa penasaran mereka yang membuat mereka menggunakan waktu hanya ingin mencari tau tentang idola mereka, akibatnya mereka yang masih sekolah sering telat membuat tugas serta lupa jika mereka harus menjalankan kewajiban mereka untuk mengurus hidup mereka sendiri. Anggota Komunitas EXO-L juga mengatakan mereka tidak jarang lupa waktu hingga lupa apa yang harus dilakukan, namun mereka juga mengatakan tidak bisa lepas dari hal-hal yang berbau tentang EXO, mereka tidak mau ketinggaltan info-info.

Menurut Gabriel Tarde semua saling hubungan sosial itu berkisar pada proses imitasi; bahkan semua pergaulan antarmanusia hanyalah berdasarkan proses imitasi. Masyarakat itu tidak lain dari pengelompokkan manusia di mana individu-individu yang satu mengimitasi yang lain dan sebaliknya. Gabriel Tarde juga berpendapat perilaku imitasi terjadi karena ada tokoh idola yang dijadikan sebagai model untuk ditiru (Sella, 2013). Pada penelitian ini diketahui bahwa dampak Boyband EXO Style bagi Komunitas EXO-L Sumatera Barat karena idola mereka yang dijadikan model bagi mereka, serta perkembangan K-pop yang dirasakan di lingkungan sekitar, proses peniruan yang mereka lakukan tidak hanya penampilan tapi juga sikap dan perilaku dari idola mereka. Style Korea yang menurut cocok dengan diri mereka sehingga menurut mereka bisa dijadikan inspirasi dalam berpakaian namun tetap disesuaikan dengan aturan serta kebiasaan, namun ada juga yang menurut mereka cukup menjadikan cara berpakain yang lebih rapi tanpa mengubah Style sendiri dari pada mengikuti karena selera masing-masing.

\section{Kesimpulan}

Dampak dari Boyband EXO style bagi anggota Komunitas EXO-L Sumatera Barat ada empat, yaitu Style, mereka merasa ada beberapa style Korea atau Boyband EXO yang bisa mereka tiru namun tetap dalam batas wajar seseaui dengan kepribasian mereka. Kedua yaitumereka terinspirasi dari musik atau lagu dari Boyband EXO karena lirik yang memotivasi serta bahasabahasa yang bisa dipelajari dari lagu-lagu EXO. Ketiga yaitu mereka bisa mengembangkan hobby

Culture \& Society: Journal of Anthropological Research Vol. 2, No. 1, Th. 2020 
seperti menyanyi dan melakukan dance cover Boyband EXO. Keempat dampak perilaku yang lainnya yaitu mereka harus menontrol pengeluaran mereka karena kebutuhan finansial untuk halhal yang mereka anggap perlu sebagai penggemar Boyband EXO. Kelima perilaku mereka yang terlihat menyamai Boyband EXO dan masyarakat Korea, keenam rasa sensitif terhadap berita Boyband EXO, adapun prilaku mereka yang sesuai dengan emosional mereka, terkadan mereka menjadi senang bahkan tiba-tiba sedih atau marah. ketujuh lupa wakti menjadikan perilaku kuran disiplin dari mereka karena mengikuti segala tentang EXO.

\section{Daftar Pustaka}

Bungin, B. (2012). Analisis Data Penelitian Kualitatif. Jakarta: PT Raja Grafindo Persada.

Febrianto, A., \& Fitriani, E. (2012). Orang Mentawai: Peladang Tradisional dan Ekonomi Pasar. Humanus, 11(2), 119-133.

Fitri, N. F., \& Adelya, B. (2017). Kematangan emosi remaja dalam pengentasan masalah. JPGI (Jurnal Penelitian Guru Indonesia), 2(2), 30-39.

Gerungan, W. A. (2010). Psikologi Sosial. Bandung: Refika Aditama.

Hariyati, S. (2015). Persepsi Masyarakat terhadap Pembangunan Jembatan Mahkota II di Kota Samarinda. Skripsi. Universitas Mulawarman.

Izzati, A., \& Armando, A. (2014). Analisis Pengaruh Musik Korea Popular Terhadap Gaya Hidup di Kalangan Remaja. Jurnal Ilmu Sosial dan Politik Universitas Indonesia, 1(1), 1-23.

Kaparang, O. M. (2013). Analisa Gaya Hidup Remaja Dalam Mengimitasi Budaya Pop Korea Melalui Televisi. Acta Diurna Komunikasi, 2(2), 1-15.

Koentjaraningrat. (2013). PengatarIlmu Antropologi. Jakarta: Rineka cipta.

Manizar, E. (2016). Mengelola Kecerdasan Emosi. Jurnal Tadrib, 2(2).

Misbach, I. (2017). Perilaku Bisnis Syariah. Al-Idarah, 5(1), 33-44.

Rahmawati, E. Y. (2017). Aktivitas Fandom dalam Mengaktualisasi Fenomena Slash Pairing Pada Akun Media Sosial Instagram (studi Etnografi Virtual pada Fandom Boyband EXO di Media Sosial Instagram). Tesis. Universitas Airlangga.

Sella, Y. P. (2013). Analisi Perilaku Dikalangan Remaja Setelah Menonton Tayangan Drama Seri Korea Di indosial (Studi Kasus Perumahan Pondok Karya Lestari Sui Kapih Samarinda). Tesis. Universitas Mulawarman.

Seob, K. G. (2014). Komunikasi Antara Budaya Korea dan Indonesia: Kajian tentang Perilaku Masyarakat Korea dan Jawa. Yogyakarta: Pusat Studi Korea Universitas Gajah Mada.

Sugiyono. (2008). Memahami Penelitian Kualitatif. Bandung: Alfabeta.

Sugiyono. (2017). Metode Penelitian Kuantitatif, Kualitatif, dan R\&D. Jakarta: Alfabeta.

Wende, F.M., Erianjoni, E. \& Nora, D. (2018). Strategi Adaptasi Mahasiswa UNP Non Muslim dalam Kegiatan Praktek Kependidikan (PLK) Pada Sekolah Praktek Lapangan di Kota Padang Fransisca. Jurnal Perspektif, https://doi.org/http://dx.doi.org/10.24036/perspektif.v1i4.56

Wijaya, N. P. (2017). Komunitas Exo-L Yogyakarta (Studi Kasus Dinamika Penggemar K-Pop di Yogyakarta). Skripsi. Institut Seni Indonesia Yogyakarta. 